\title{
sciendo
}

CIVIL AND ENVIRONMENTAL ENGINEERING REPORTS

E-ISSN 2450-8594

CEER 2019; 29 (3): 252-271

DOI: $10.2478 /$ ceer-2019-0040

Original Research Article

\section{AGGLOMERATION OF SILICON DIOXIDE NANOSCALE COLLOIDS IN CHEMICAL MECHANICAL POLISHING WASTEWATER: INFLUENCE OF pH AND COAGULANT CONCENTRATION}

\author{
Mohamad Zuki NOOR AINA ${ }^{1}$, Jing Yao SIN ${ }^{1}$, Amane JADA², \\ Arezoo Fereidonian DASHTI ${ }^{1}$, Mohd Omar FATEHAH ${ }^{1 *}$ \\ ${ }^{1}$ School of Civil Engineering, Universiti Sains Malaysia, Pulau Pinang, Malaysia \\ ${ }^{2}$ Institut de Sciences des Materiaux de Mulhouse, CNRS UMR 7361, France
}

\begin{abstract}
Chemical mechanical polishing (CMP) wastewater generated from semiconductor manufacturing industries is known to contain residual organic and inorganic contaminants, i.e. photoresists, acids, including silicon dioxide $\left(\mathrm{SiO}_{2}\right)$, nanoparticles (NPs) and others. Nanoscale colloids in CMP wastewater have strong inclination to remain in the suspension, leading to high turbidity and chemical oxygen demand (COD). Although various types of pre-treatment have been implemented, these nanoparticles remain diffused in small clusters that pass through the treatment system. Therefore, it is crucial to select suitable $\mathrm{pH}$ and coagulant type in the coagulation treatment process. In this research zeta potential and dynamic light scattering measurements are applied as preliminary step aimed at determining optimum $\mathrm{pH}$ and coagulant dosage range based on the observation of inter particle-particle behavior in a CMP suspension. The first phase of the conducted study is to analyze nanoscale colloids in the CMP suspension in terms of zeta potential and z-average particle size as a function of $\mathrm{pH}$ within a range of 2 to 12 . Two types of coagulants were investigated - polyaluminum chloride (PACl) and ferrous sulfate heptahydrate $\left(\mathrm{FeSO}_{4} \cdot 7 \mathrm{H}_{2} \mathrm{O}\right)$. Similar $\mathrm{pH}$ analysis was conducted for the coagulants with the same $\mathrm{pH}$ range separately. The second phase of the study
\end{abstract}

1* Corresponding author: School of Civil Engineering, Universiti Sains Malaysia, Seri Ampangan, 14300 Nibong Tebal, Pulau Pinang, Malaysia, e-mail cefatehah@usm.my, tel. +6045996293 
involved evaluating the interaction between nanoscale colloids and coagulants in the suspension. The dynamics of zeta potential and corresponding particle size were observed as a function of coagulant concentration. Results indicated that CMP wastewater is negatively charged, with average zeta potential of $-59.8 \mathrm{mV}$ and $149 \mathrm{~d} . \mathrm{nm}$ at $\mathrm{pH}$ value of 8.7. The interaction between CMP wastewater and $\mathrm{PACl}$ showed that positively charged $\mathrm{PACl}$ rapidly adsorbed colloids in the wastewater, reducing the negative surface charge of nanoscale clusters. The interaction between CMP wastewater and $\mathrm{FeSO}_{4} \cdot 7 \mathrm{H}_{2} \mathrm{O}$ showed that larger dosage is required to aggregate nanoscale clusters, due to its low positive value to counter negative charges of CMP wastewater.

Keywords: CMP wastewater, nanoscale colloids, $\mathrm{pH}$, zeta potential, particle size, ferrous sulfate heptahydrate, $\mathrm{PACl}$

\section{INTRODUCTION}

In recent years, global increase of engineered nanoparticles (ENPs) in products and daily applications manufactured for human consumption has added to rising concern of nanomaterials being released into the environment. Routes and pathways for their introduction include accidental spillage and industrial effluents (Keller et al., 2010). Waste disposal sources include semiconductor, textile, agriculture and other types of industries (Brar et al., 2010). Several studies have been conducted on the characteristics, properties, behavior, fate, transport and stability of engineered nanoparticles in synthetic and environmental aqueous suspensions. These studies, however, provide limited information as they only take into account certain interacting factors such as, for example, $\mathrm{pH}$ and ionic strength (Mohd Omar et al., 2014; Loosli et al., 2014; Orehova and Stoll, 2016). In actual environmental aqueous suspensions dynamic behaviors of nanosized particle clusters such as agglomeration, deagglomeration, stability are subject to change governed by external factors in the aqueous medium, due to their complexity (Liu et al., 2016).

There is some research that advances into analyzing the behavior of nanoparticles containing water and wastewater in order to further understand their persistence and pertinence in aqueous medium. In real life situations, nanoparticles such as silica remain stable in tap water due to their low pHPZC and low Hamaker constant (Zhang et al., 2008). Particles' removal and their kinetic behavior was studied in CMP wastewater.

Semiconductor industry constitutes one of the pillars of national economic growth in almost any country; it grows proportionately to national development rates and is expected to further expand in the next few years (Ahmad et al., 2011). 
Huge industries had particularly large impact on river systems which became the receiving bodies of pollutants. Chemical mechanical polishing involves ultrafine colloidal silicon dioxide $\left(\mathrm{SiO}_{2}\right)$ particles. The properties of nanoparticles depend on the $\mathrm{pH}$ of the environment. The behavior of nanosized $\mathrm{SiO}_{2}$ colloids were studied in order to predict particle coagulation behavior and to obtain better insight into coagulation mechanisms based on the dynamics of $\mathrm{pH}$ dependent surface charges. The effect of $\mathrm{pH}$ variation on zeta potential and particle size were investigated. Silica nanoparticles from CMP wastewater come from wafer cleaning in semiconductor manufacturing processes (Liu et al., 2013; Liu et al., 2016). Hence, properties and behavior of silica need to be understood before conducting the research. Silica present in natural aqueous systems eventually ends up in drinking water, although consuming silica is not harmful for human health. It is, however, hazardous in other ways - inhaling fine particles of silica may lead to silicosis, bronchitis or cancer as the nanoparticles become trapped in lungs and continuously damage lung tissue (Mulloy, 2003; Hollingsworth et al., 2005; Lin et al., 2006; Decan et al., 2016). Short-circuiting and other defects may also pose inherent risk if water is polluted. Given all that, zeta potential and particle size become important parameters in treating CMP wastewater.

Produced semiconductors must be rinsed, which requires huge volumes of ultrapure water - a $300 \mathrm{~mm}$ wafer requires approximately 2200 gallons of water in total, including 1500 gallons of ultrapure water. Ultrapure water is widely used for polishing semiconductor (Hernon et al., 2010) and hence large amounts of wastewater is generated and discharged by semiconductor industry. In recent years, the amount of CMP produced from the semiconductor manufacturers has increased proportionately to the growth of this sector resulting from economic development and urbanization.

Chemical mechanical polishing (CMP) is a planarization technology widely used in the production of semiconductors. Available studies estimate that CMP process consumes as much as $40 \%$ of ultrapure water used in semiconductor manufacturing (Lai and Lin, 2003). Hence, it is crucial to treat CMP wastewater so that it can be reused, in order to reduce the amount of water consumption. The quality of semiconductor wastewater becomes the point of concerned of the researchers as it is important to understand the behavior of wastewater before it undergoes any treatment.

Semiconductor industry not only consumes ever increasing amounts of water but, in consequence, is also responsible for discharging large volume of wastewater. Industrial water consumption and environmental pollution are both closely monitored by certain agencies which demand the reduction of the volume of consumed water and levels of suspended solids in discharged wastewater (Mekonnen, 2015). 
CMP wastewater is highly alkaline, with high total solids content and turbidity (Yang et al., 2003; Chou et al., 2009). High total solids content is the consequence of the presence of fine particles and chemicals such as oxidizing agents (Lai and Lin, 2003). Suspended solids concentration is, however, very low in CMP wastewater as the size of fine particles are in the range of 10 to $100 \mathrm{~nm}$ (Lin and Yang, 2004). As for high turbidity of wastewater, CMP wastewater has a dark, milky coffee color due to the presence of oxide (Chou et al., 2010). Chemical oxygen demand (COD) for CMP wastewater is very high due to high inorganic and organic content (Lin and Kiang, 2003; Lin and Jiang, 2003; Chou et al., 2009). CMP wastewater has high negative surface charge that repels particles from one another and contributes to the stability of the suspension (Liu and Lien, 2006; Liu and Tourbin, 2012). It also prevents particles from aggregating. Thus, zeta potential of CMP wastewater also has high negative charge.

Total solids in CMP are extremely high (Hu et al., 2005; Yang and Yang, 2004). This is so because CMP contains many fine particles and contaminants. The wastewater has an appearance of diluted milk due to oxide particles content (Chou et al., 2010), high turbidity, $\mathrm{pH}$ range between 8 and 9 and high COD (Wong et al., 2013).

The efficiency of ferrous sulfate heptahydrate as coagulant in induced aggregation onto the nanoscale $\mathrm{SiO}_{2}$ colloids was investigated and compared with commercial polyelectrolyte $\mathrm{PACl}$ in the same dosage range. There are many studies concerning the stability of nanoparticles in aqueous suspensions in terms of agglomeration, deagglomeration and stability in environmental conditions (Bian et al., 2011).

In order to solve this question, many studies dedicated to treating wastewater were conducted. Several concern treating CMP wastewater in several ways. Applied methods include air flotation (Ghazy et al., 2010; Wang, 2017), electrocoagulation (Kabdasli et al., 2012; Chou et al., 2010), and ultrafiltration (Chou et al., 2010). There are also certain studies in which several methods of treat semiconductor wastewater were combined (Hu et al., 2005; de Luna et al., 2009). In others, silica from wastewater was separated using another coagulant, such as aluminum chloride (Liu and Tourbin, 2012), cetyltrimethylammonium bromide (Liu et al., 2013) and polyaluminum chloride (Stewart et al., 2011).

Pre-treatment of CMP wastewater included dissolved air flotation (DAF) (Chuang et al., 2002; Al-shamrani et al., 2002; Liu and Lien, 2006; Ghazy et al., 2010; Tsai et al., 2007), electrocoagulation (Lai and Lin, 2004; Chou et al., 2009; Liu et al., 2015; Mollah et al., 2001; Veps, 2012; Kabdasli and Tunay, 2012), ultrafiltration (Bruggen et al., 2005; Brujin et al., 2005; Wu et al., 2010) and coagulationflocculation (Tzoupanos and Zouboulis, 2008; Jiang, 2015; Xiong et al., 2017). 
The use of zeta potential in interpreting coagulation-flocculation efficiency in water and wastewater treatment has recently triggered significant interest (Lopez-Maldonado et al., 2014; Palomino et al., 2011; Liu et al., 2016) in the scope of nanoparticle removal (Popowich et al., 2015). The stability of nanomaterials is governed by their properties, which subsequently determine their fate and transportation in aqueous suspensions (Choudhury et al., 2010). Dynamic light scattering and static light scattering have been used to monitor changes in size in aggregate processes (Yu et al., 2006; Smith et al., 2009). Most solids suspended in water have negative charges, so they constantly repel one another (Cherr et al., 2010). The repulsion prevents the particles from aggregating causing permanent suspension in water (Akbari et al., 2011). The rule of coagulation-flocculation is that the forces stabilizing the suspended particles are overcome, allowing particles to collide with one other to create flocs, which then settle due to gravity and can be easily removed (Ostolska, 2014).

$\mathrm{PACl}$ is an aluminum polymer used as coagulant in water treatment facilities. The reaction $\mathrm{PACl}$ undergoes during coagulation is quite complex and not has not been fully explained until today (Yi Geng, 2005). PACl has many advantages over alum in coagulant usage since it has a wider $\mathrm{pH}$ effectiveness than alum (Thomas, 2002). PACl generates less sludge compared to alum. Also, the performance of $\mathrm{PACl}$ is not affected by low temperature, which is the case with alum (Peter, 2001). However, $\mathrm{PACl}$ is very costly in comparison to other coagulants (Shi et al., 2007). Moreover, $\mathrm{PACl}$ is not as effective as alum in terms of removing dissolved organic matter (Peter, 2001).

In this study, ferrous sulfate and polyaluminum chloride were selected as coagulants to treat CMP wastewater. Ferrous sulfate is an iron based coagulant which can convert ferrous ions into ferric ions, of better capacity to neutralize particle charge (Parmar et al., 2011).

Research objectives of this study include conducting preliminary analysis on zeta potential and particle size profiles as a function of $\mathrm{pH}$ of wastewater suspension and stock solutions of coagulants independently. This is followed by observation and comparison of interaction behavior (i.e. agglomeration and deagglomeration) of silicon dioxide nanoparticles in CMP wastewater with coagulants (i.e. ferrous sulfate and polyaluminum chloride). The innovation of this study consists in the fact that zeta potential and corresponding particle size provides actual insight into optimum $\mathrm{pH}$ range for both wastewater and coagulants by simplifying the integration of both suspensions in order to enhance coagulation efficiency at minimal doses. 


\section{MATERIALS AND METHODS}

\subsection{Materials}

\subsubsection{Chemical mechanical polishing wastewater}

CMP wastewater samples were collected from a multinational semiconductor company located in the Kulim High Technology Industrial Park, Kedah, Malaysia. The samples were collected at separate discharge points before entering equalization tank, which is the final receiving end of all wastewater channels in the manufacturing plant. All the samples were kept at $4^{\circ} \mathrm{C}$ in 251 carboys.

\subsubsection{Coagulants}

Two types of coagulants were used in the study to interact with $\mathrm{SiO}_{2}$ nanoparticles in CMP wastewater: ferrous sulphate heptahydrate $\left(\mathrm{FeSO}_{4} \cdot 7 \mathrm{H}_{2} \mathrm{O}\right)$ and polyaluminum chloride. $\mathrm{FeSO}_{4} \cdot 7 \mathrm{H}_{2} \mathrm{O}$ powder was obtained as by-product from a titanium dioxide manufacturing plant located in the east coast of Malaysia. The powder looked like green vitrol (blue-green crystals). Stock solution with a concentration of $500 \mathrm{mg} / \mathrm{L}$ was prepared by weighing $250 \mathrm{mg}$ in milli-Q water (MilliQ). PACl (18\%) was obtained from Darco Sdn Bhd. Other chemicals, i.e. the acid and base, are standard chemicals and were used for $\mathrm{pH}$ alterations in experimental work.

\subsection{Methodology}

\subsubsection{Zeta potential and z-average hydrodynamic diameter measurements}

In this study zetasizer Nano ZS (Malvern, UK) was used to determine zeta potential and $z$-average hydrodynamic diameter of CMP wastewater and coagulants. Z-average hydrodynamic diameter is measured using dynamic light scattering (DLS) technique. The principle of this state of the art technique is to measure Brownian motion of fine particles that keep moving in aqueous suspension. The sample in a capillary cell was illuminated by laser beam and fluctuations of scattered light were detected at fixed scattering angle $(\Theta)$ by fast photon detector. Zetasizer Nano ZS works by using red laser light $(625 \mathrm{~nm})$ with a scattering angle of $173^{\circ}$. The wavelength of the scattered light is directed towards the particles; the change is related to the particle size. From the microscopic point of view, the particles scatter the light and then imprint information on their motion. Therefore, analysis of the fluctuation of the scattered light yields information on the particles. Particle sizes are then determined on the basis of the Stoke-Einstein equation for the diffusion coefficient. 


\subsubsection{Chemical mechanical polishing wastewater}

In all the experiments $100 \mathrm{~mL}$ of CMP wastewater was used. Initial $\mathrm{pH}$, zeta potential and z-average hydrodynamic diameter of CMP wastewater were identified and recorded using a $\mathrm{pH}$ meter (Mettler-Toledo, Switzerland). $1 \mathrm{~mL}$ aliquots were extracted using a 1cc syringe (Terumo) to transfer them into zeta capillary cells, which were then placed in the cell compartment of Zetasizer Nano ZS (Malvern, UK) to be examined for zeta potential and z-average hydrodynamic diameter measurements at $25^{\circ} \mathrm{C}$. The device is set to take 5 measurements with 10 repetitive runs for each measurement in order to obtain consistent readings. The average value was then calculated for each sample and $\mathrm{pH}$ of the CMP suspension adjusted towards acid from the initial $\mathrm{pH}$. Zeta potential and corresponding z-average hydrodynamic diameter were measured at each $\mathrm{pH}$ value. This process was then repeated for CMP suspension altered from its initial $\mathrm{pH}$ towards alkali.

Characterization experiments of $\mathrm{FeSO}_{4} \cdot 7 \mathrm{H}_{2} \mathrm{O}$ and $\mathrm{PACl}$ stock solutions for zeta potential and z-average hydrodynamic diameter as a function of $\mathrm{pH}$ were also conducted as a part of this study. The measurement procedures for zeta potential and particle size consist of the same steps as in case of CMP wastewater. Collected data was tabulated and presented in graphical forms.

\subsubsection{Chemical mechanical polishing wastewater and coagulant suspensions}

The interaction between CMP wastewater and coagulants took place in the next stage of methodology. In the first set of experiments CMP wastewater was measured at $\mathrm{pH} 8.7$ with stock solution of $\mathrm{FeSO}_{4} \cdot 7 \mathrm{H}_{2} \mathrm{O}$ set at $\mathrm{pH}$ 5. Initial values of $\mathrm{pH}$, zeta potential and particle size in the absence of ferrous sulphate were measured for CMP wastewater. Ferrous sulphate solution was added to CMP suspension in small successive doses until maximum concentration of $35 \mathrm{mg} / \mathrm{L}$ was reached. The value of $\mathrm{pH}$, zeta potential and particle size were all recorded on the way.

In the next set of experiments CMP wastewater underwent similar procedure, but with stock solution of $\mathrm{PACl}$. Initial values of $\mathrm{pH}$, zeta potential and particle size were measured in the absence of $\mathrm{PACl}$ for $\mathrm{CMP}$ wastewater. Polyaluminum chloride solution was then added to CMP suspension in small successive doses until maximum concentration of $35 \mathrm{mg} / \mathrm{L}$ was reached. The value of $\mathrm{pH}$, zeta potential and particle size were all measured on the way. 


\section{RESULTS AND DISCUSSION}

\subsection{Zeta potential and particle size measurements as a function of $\mathbf{p H}$}

\subsubsection{Characteristics of CMP wastewater}

CMP wastewater was analyzed for its functional groups with the use of Fouriertransform infrared spectroscopy (FTIR). Potassium bromide (KBr) based pellets were prepared by applying pressure of $10 \mathrm{~kg} / \mathrm{cm}^{2}$ for about $30 \mathrm{~s}$. Pure $\mathrm{KBr}$ tablet was used as blank for background subtraction. Loopfuls from yeast isolates cultured on SDA supplemented with chloramfenicol were used and placed on $\mathrm{KBr}$ discs.

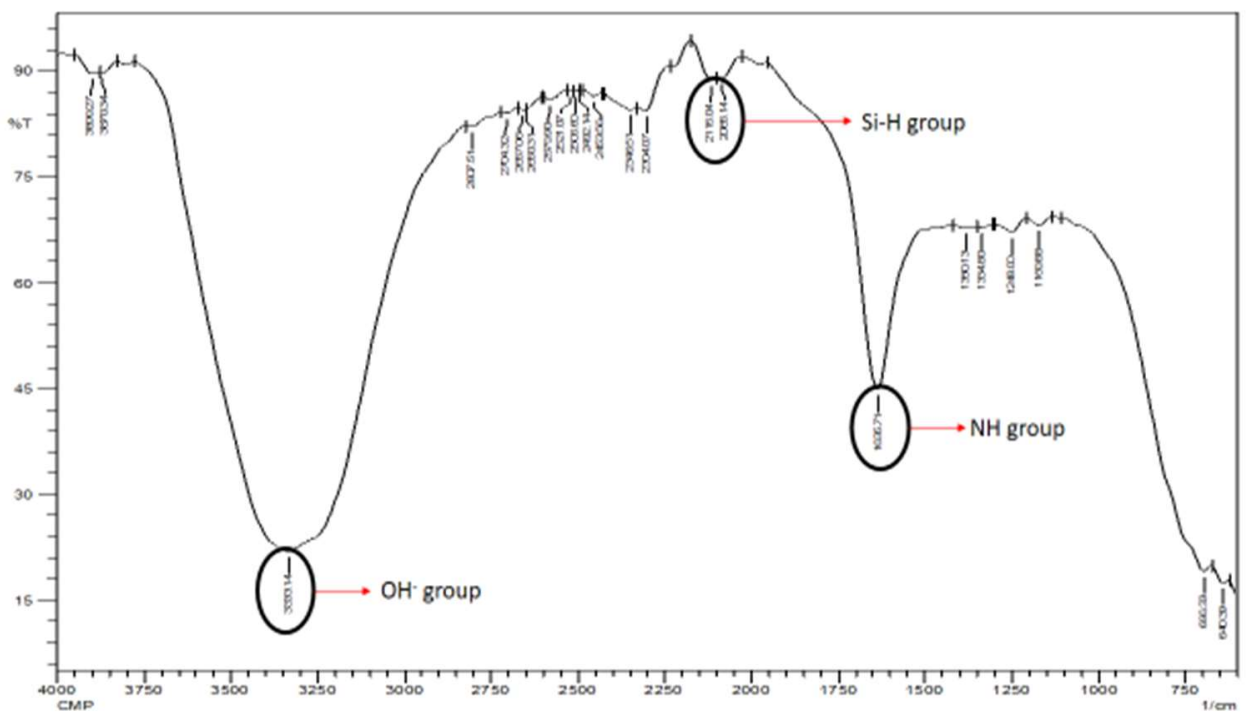

Fig. 3.1. FTIR of CMP wastewater

CMP wastewater mainly contains suspended nano-sized solids originating from slurry abrasive particles of $\mathrm{SiO}_{2}, \mathrm{Al}_{2} \mathrm{O}_{3}$ or $\mathrm{CeO}_{2}$, depending on $\mathrm{CMP}$ applications (Wen et al., 2009). Based on the resulting FTIR (Fig. 3.1) the presence of silica group (Si-H group) in the CMP wastewater ranging from 2085 to $2115 \mathrm{~cm}^{-1}$ was confirmed. Other than that, due to the $\mathrm{NaOH}$ added in the wastewater sample during $\mathrm{pH}$ adjustment, a hydroxyl group was also present in the wastewater at $3333 \mathrm{~cm}^{-1}$.

Figures 3.2 (a) and (b) illustrate zeta potential and particle size profiles of CMP wastewater measured at various $\mathrm{pH}$ values in a range of 2 to 12 respectively. 

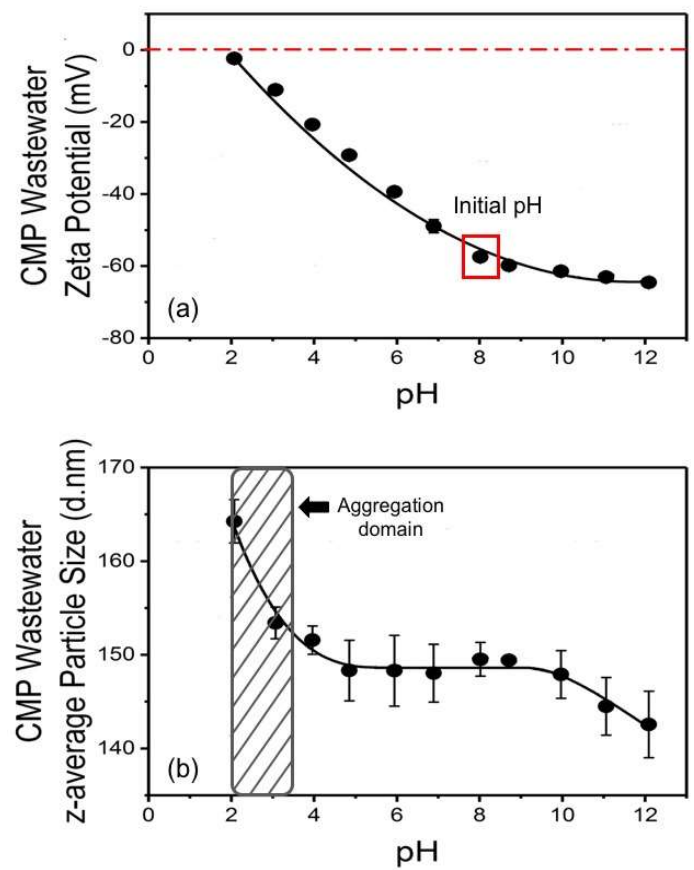

Fig. 3.2. Variation of (a) zeta potential and (b) z-average particle size of silicon dioxide NPs in CMP wastewater in a $\mathrm{pH}$ range of 2 to 12 . Recorded initial values amounted to $\mathrm{pH} 8.7$, zeta potential $-59.8( \pm 0.9) \mathrm{mV}$ and particle size of $149.4( \pm 0.2) \mathrm{d} . \mathrm{nm}$.

The surface charge of silicon dioxide nanoparticles are negatively charged. No point of charge (PZC) was detected closely, however the lowest zeta potential was detected closest to $0 \mathrm{mV}$ at $\mathrm{pH} 2$

Figures 3.2 (a) and (b) present zeta potential and particle size variation of silicon dioxide NPs present in CMP wastewater as a function of $\mathrm{pH}$. Initial $\mathrm{pH}$ value of CMP wastewater was found to be 8.7, with average zeta potential of -59.8 $( \pm 0.9)$ $\mathrm{mV}$ and z-average hydrodynamic diameter of $149.4( \pm 0.2)$ d.nm. This showed that CMP wastewater was alkaline with highly negative surface charge. High negative zeta potential also indicates that CMP wastewater particles were electrically stable. Hence, suspension stability between CMP wastewater particles was high and aggregation would not occur easily. The value of $\mathrm{pH}$ of the CMP suspension was adjusted towards acid, from $\mathrm{pH} 8.7$ to $2 . \mathrm{H}^{+}$and $\mathrm{Cl}^{-}$ions released from the added acid solution in the aqueous suspensions reacted to opposite charges present in the CMP suspension (i.e. $\mathrm{Si}^{4+}$ and $\mathrm{O}^{2-}$ ). At $\mathrm{pH} 2$ zeta potential was recorded at $-2.4( \pm 0.1) \mathrm{mV}$. In the same $\mathrm{pH}$ range, as illustrated on fig. 3.2 (b), it can be observed that particle size of $\mathrm{SiO} 2 \mathrm{NPs}$ did not change significantly 
until $\mathrm{pH}$ was reduced to 2 , when a small increment was recorded from 152 to $167.4( \pm 2.3)$ d.nm. This can be explained by the increased amount of $\mathrm{H}^{+}$ions interacting the $\mathrm{O}^{2-}$ ions.

After adjusting $\mathrm{pH}$ of the CMP suspension towards alkaline from $\mathrm{pH} 8.7$ to 12 , negative charge increased to $-60 \mathrm{mV}$ (fig. 3.2 (a)). Decrease in diameters of particles was observed, from 148 to $143 \mathrm{~d} . \mathrm{nm}$ for $\mathrm{pH}$ between 10 and 12 .

\subsection{2. $\mathrm{FeSO}_{4} \cdot 7 \mathrm{H}_{2} \mathrm{O}$ coagulant}

Fig. 3.3 (a) and (b) indicate variation of zeta potential and z-average hydrodynamic diameter of suspension with concentration of $500 \mathrm{mg} / \mathrm{L}$ as a function of within a range of 2 to 12. The solution was adjusted with $\mathrm{HCl}$ and $\mathrm{NaOH}$ (graduated chemicals). Initial $\mathrm{pH}$ value of $\mathrm{FeSO}_{4} \cdot 7 \mathrm{H}_{2} \mathrm{O}$ was recorded at $\mathrm{pH}$ 5.4. Initial corresponding zeta potential and z-average hydrodynamic diameter amounted to $+11.5( \pm 0.9) \mathrm{mV}$ and $625.7( \pm 16)$ d.nm respectively. The $\mathrm{pH}$ of $\mathrm{FeSO}_{4} \cdot 7 \mathrm{H}_{2} \mathrm{O}$ suspension was then reduced from 5.4 to 2 by means of $\mathrm{HCl}$. In fig. 3.3 (a), at $\mathrm{pH} 6$, zeta potential is at $+5 \mathrm{mV}$, with corresponding increase in the particle size, as presented in fig. 3.2 (b).
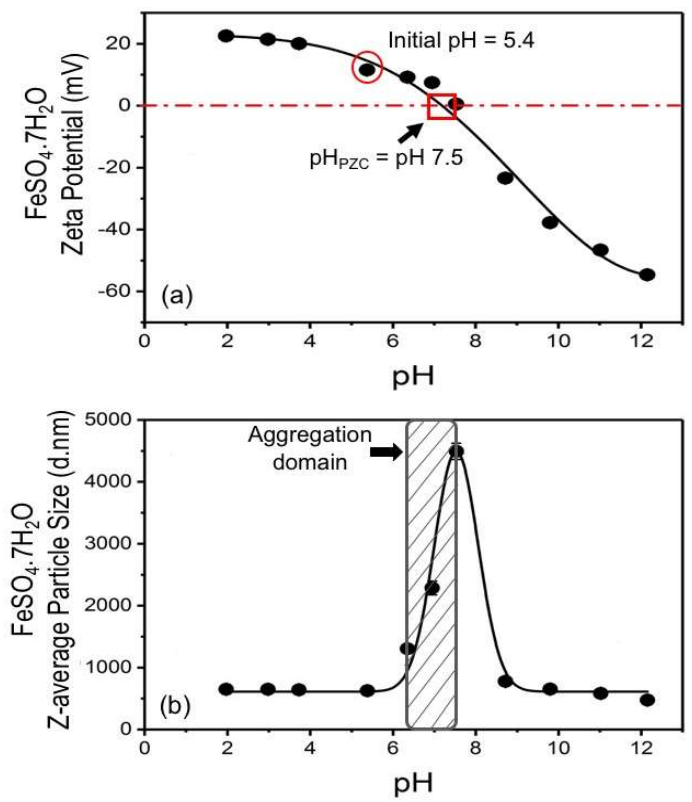

Fig. 3.3. Variation of (a) zeta potential and (b) z-average hydrodynamic diameter of ferrous sulphate hydrated in $\mathrm{pH}$ range of 2 to 12 . Initial $\mathrm{pH}$ was recorded at 5.4, with surface charge of $+11.5( \pm 0.9) \mathrm{mV}$ and particle size of $625.7( \pm 16)$ d.nm, while $\mathrm{pH}_{\mathrm{PZC}}$ occurred at $\mathrm{pH} 7.5$ 
As the $\mathrm{pH}$ value was adjusted towards alkaline, zeta potential decreased and converted from positively to negatively charged at $\mathrm{pH} 7.5$. The highest $\mathrm{z}$-average hydrodynamic diameter measured was at $4493( \pm 130)$ d.nm. When $\mathrm{pH}$ value was adjusted further to alkaline condition, the particle decreased due to partial deagglomeration. At $\mathrm{pH} 12$ surface charge and particle size amounted to -54.6 $( \pm 0.4) \mathrm{mv}$ and $475.1( \pm 14)$ d.nm, respectively.

\subsubsection{PACl coagulant}

Fig. 3.4 (a) and (b) presents zeta potential and z-average hydrodynamic diameter of $\mathrm{PACl}$ solution with a concentration of $500 \mathrm{mg} / \mathrm{L}$ in $\mathrm{pH}$ range of 2 to 12 . The variation of zeta potential and corresponding $\mathrm{z}$-average hydrodynamic diameter of $\mathrm{PACl}$ were observed.
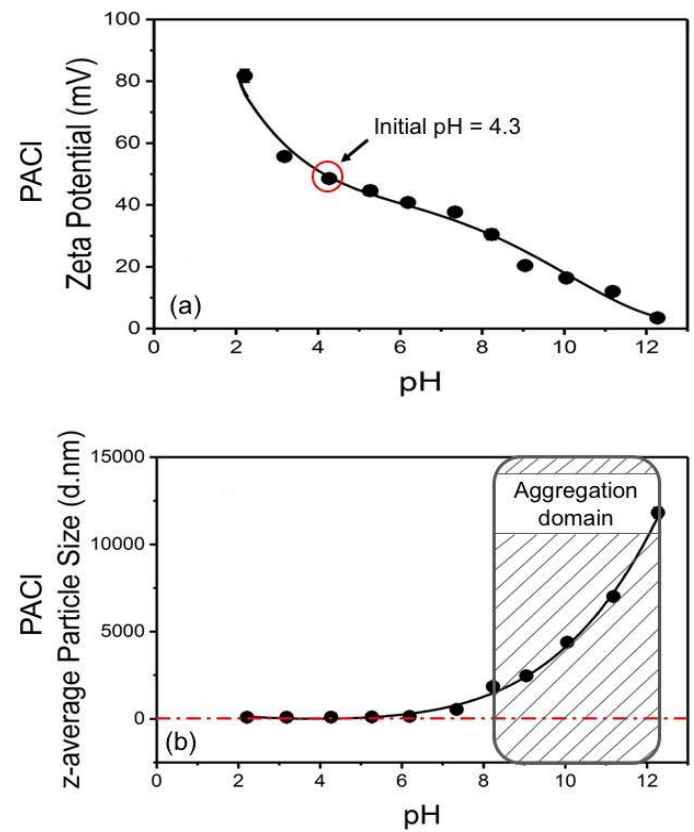

Fig. 3.4. Variation of (a) zeta potential and (b) z-average hydrodynamic diameter of $\mathrm{PACl}$ in $\mathrm{pH}$ range of 2 to 12 . Surface charge remained positive from $82( \pm 2) \mathrm{mV}$ at $\mathrm{pH} 2$ to 12. No PZC was detected

Based on the results, the initial $\mathrm{pH}$ of the $\mathrm{PACl}$ solution was documented at $\mathrm{pH} 4.3$, with zeta potential value $+48.5( \pm 1.3) \mathrm{mV}$ and $\mathrm{z}$-average hydrodynamic diameter of $101.7( \pm 3)$ d.nm, indicating that $\mathrm{PACl}$ is an acidic solution and contains positively charged particles. Compared to $\mathrm{FeSO} 4 \cdot 7 \mathrm{H}_{2} \mathrm{O}$ (Fig. 3.3), the surface charge of $\mathrm{PACl}$ was positive which is more suitable to counter the negative 
surface charges in the CMP wastewater (Fig. 3.2). Due to the higher value of zeta potential possess by $\mathrm{PACl}$, it is expected that the positive charges would interact and neutralize the negative charged particles with higher efficiency. When the $\mathrm{pH}$ value was increased to $\mathrm{pH} 12$ from the initial $\mathrm{pH}$, the zeta potential gradually decreased approaching $0 \mathrm{mV}$. At $\mathrm{pH} 12.3$, the zeta potential was observed to be $+3.5( \pm 0.3) \mathrm{mV}$ and z-average hydrodynamic diameter of $11822( \pm 304.6)$ d.nm (Fig. 3.4 (b)). Between pH10 and 12, there was a significant change in particle size in the $\mathrm{PACl}$ suspension. This was due to the reducing surface charge affected by the $\mathrm{pH}$ change. At $\mathrm{pH} 9$, the zeta potential is lower than $+20( \pm 1) \mathrm{mV}$. As the zeta potential decreased, the electrical repulsion force among the particles became weaker and tended to aggregate more extensively leading to agglomeration. In order to investigate the characterization of $\mathrm{PACl}$ at lower $\mathrm{pH}$ values, $\mathrm{HCl}$ was added successively to alter the $\mathrm{pH}$ of the suspension. The zeta potential of $\mathrm{PACl}$ increased while the z-average hydrodynamic diameter dropped accordingly to the $\mathrm{pH}$ reduction. At $\mathrm{pH} 2.2$, the zeta potential was found at $+81.8( \pm 2) \mathrm{mV}$ and the z-average hydrodynamic diameter was at $86.8( \pm 12.5)$ d.nm. During this low $\mathrm{pH}$ region, high zeta potential caused high repulsive forces between the particles. Furthermore, smaller particle size also possessed weaker van der Waals forces hence the attractive forces were weak. This creates greater stability in the suspension among the particles within this $\mathrm{pH}$ region.

\subsection{Interaction between CMP Wastewater and Coagulants as a Function of Coagulant Concentration}

\subsubsection{CMP-FeSO $\mathrm{C}_{4} \cdot 7 \mathrm{H}_{2} \mathrm{O}$ Suspensions}

In the absence of $\mathrm{FeSO}_{4} \cdot 7 \mathrm{H}_{2} \mathrm{O}$, the initial $\mathrm{pH}$ value of the $\mathrm{CMP}$ suspension was pH8.8. The experiment was carried out by adding $\mathrm{FeSO}_{4} \cdot 7 \mathrm{H}_{2} \mathrm{O}$ between 0.1 to $10 \mathrm{mg} / \mathrm{L}$ into the CMP suspension. Fig. 3.5 (a) shows the effect of $\mathrm{FeSO}_{4} \cdot 7 \mathrm{H}_{2} \mathrm{O}$ towards the $\mathrm{pH}$ value in the CMP suspension. When the acidic $\mathrm{FeSO}_{4} \cdot 7 \mathrm{H}_{2} \mathrm{O}$ was added, the $\mathrm{pH}$ values declined gradually. The changes were slightly due to the affect of $\mathrm{FeSO}_{4} \cdot 7 \mathrm{H}_{2} \mathrm{O}$ as a weak acid.

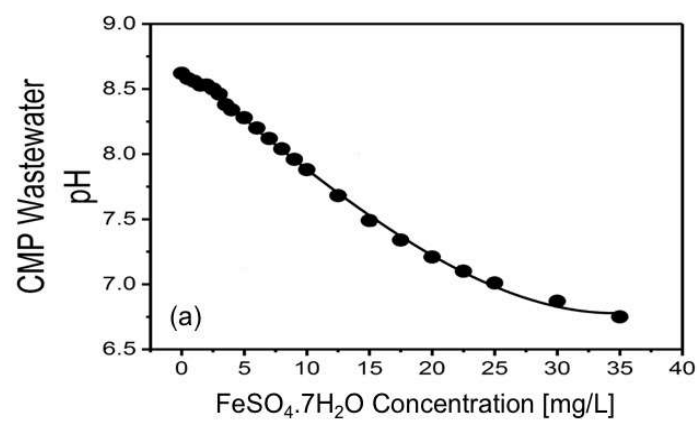



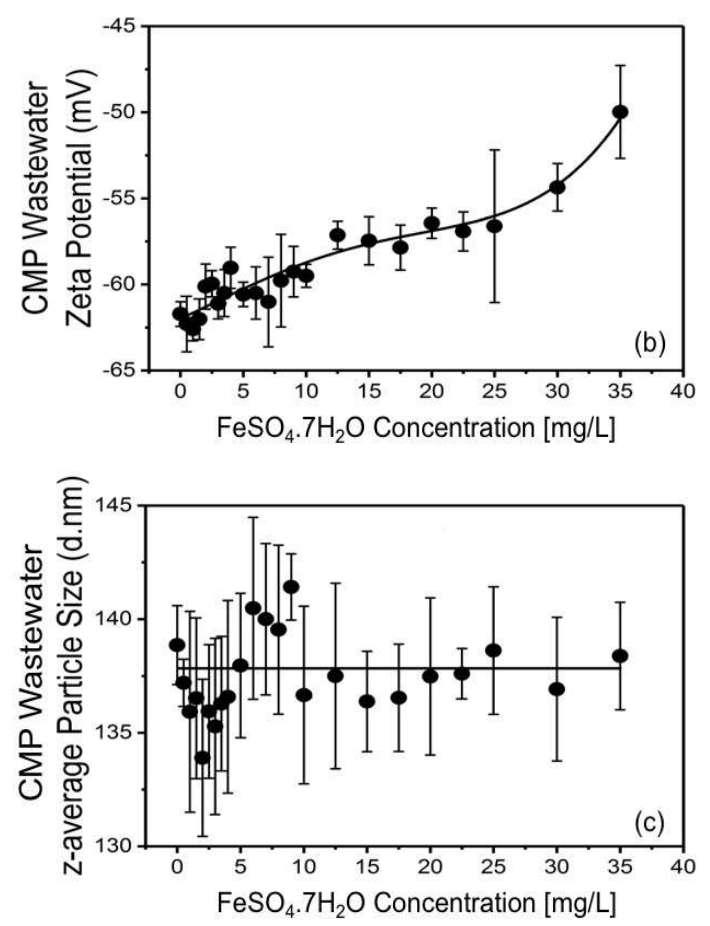

Fig. 3.5. Variation of (a) $\mathrm{pH}$ values (b) zeta potential and (c) z-average hydrodynamic diameter of CMP suspensions as function of $\mathrm{FeSO}_{4} \cdot 7 \mathrm{H}_{2} \mathrm{O}$ concentration $[\mathrm{mg} / \mathrm{L}]$. Increasing concentrations of $\mathrm{FeSO}_{4} \cdot 7 \mathrm{H}_{2} \mathrm{O}$ decrease $\mathrm{pH}$ of CMP wastewater proportionately. Zeta potential differed slightly while z-average hydrodynamic diameter remained unaffected

Based on the results, initial average zeta potential of CMP wastewater was found to be $-59.6( \pm 0.3) \mathrm{mV}$. As $\mathrm{FeSO}_{4} \cdot 7 \mathrm{H}_{2} \mathrm{O}$ was added into the suspension, changes in zeta potential were recorded and corresponding particle sizes were plotted on a graph, as shown in figure 3.5 (c). As shown in the data set, zeta potential values were proportionate to added doses of $\mathrm{FeSO}_{4} \cdot 7 \mathrm{H}_{2} \mathrm{O}$ solution. The final zeta potential of mixed suspension amounted to $-58.9( \pm 0.5) \mathrm{mV}$, with $\mathrm{FeSO}_{4} \cdot 7 \mathrm{H}_{2} \mathrm{O}$ concentration at $10 \mathrm{mg} / \mathrm{L}$. Positively charged $\mathrm{FeSO}_{4} \cdot 7 \mathrm{H}_{2} \mathrm{O}$ particles appeared to feebly interact with negatively charged CMP suspension. This could be due to high repulsive energy barrier established by surface charge of CMP wastewater. In fig. 3.5 (c), in the absence of $\mathrm{FeSO}_{4} \cdot 7 \mathrm{H}_{2} \mathrm{O}$, the average particle size of CMP wastewater was $149.2( \pm 0.7)$ d.nm at $\mathrm{pH} 8.8$. Fig. 3.5 (c) presents changes in zaverage hydrodynamic diameter of CMP suspension as function of $\mathrm{FeSO}_{4} \cdot 7 \mathrm{H}_{2} \mathrm{O}$ concentration. Similar to zeta potential results in fig. 3.4 (b), z-average 
hydrodynamic diameter was unaffected by increasing $\mathrm{FeSO}_{4} \cdot 7 \mathrm{H}_{2} \mathrm{O}$ concentrations. This is due to constant value of zeta potential, which sustained the charges despite increasing volume of $\mathrm{FeSO}_{4} \cdot 7 \mathrm{H}_{2} \mathrm{O}$. Therefore, colloidal particles continued to repel one another. Under these circumstances aggregation of particles was limited and lead to them remaining constant in size.

\subsubsection{CMP-PACI Suspensions}

Fig. 3.6 (a) shows $\mathrm{pH}$ change in CMP suspension after adding $\mathrm{PACl}$ from stock solution of $500 \mathrm{mg} / \mathrm{L}$. The value of $\mathrm{pH}$ of CMP suspension in the absence of $\mathrm{PACl}$ was recorded at $\mathrm{pH} 8.8$. After adding $\mathrm{PACl}$ of concentration in a range of 0.5 to $35 \mathrm{mg} / \mathrm{L}$ to the CMP suspension to the CMP suspension to the CMP suspension. As presented in fig. 3.6 (a), $\mathrm{pH}$ value declined as the dosage increased. At PACl dose of $35 \mathrm{mg} / \mathrm{L} \mathrm{pH}$ value was reduced to 5.1. Reduced $\mathrm{pH}$ value resulted from an acid-base reaction between $\mathrm{PACl}$ and $\mathrm{CMP}$ wastewater.
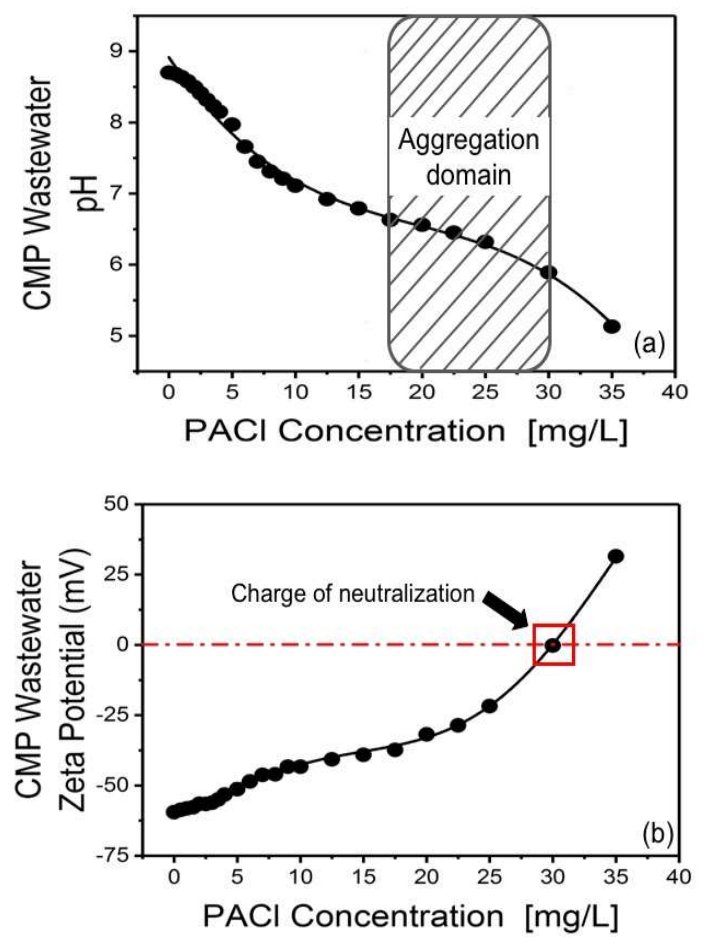


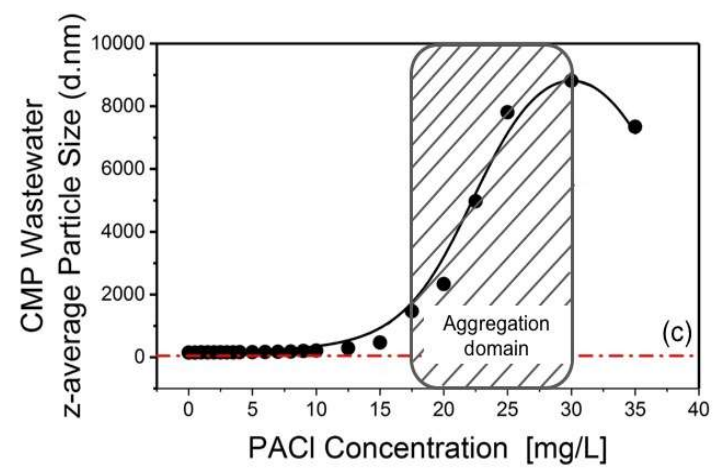

Fig. 3.6. Variation of (a) $\mathrm{pH}$ values, (b) zeta potential and (c) z-average hydrodynamic diameter of CMP suspension as function of $\mathrm{PACl}$ concentration $[\mathrm{mg} / \mathrm{L}]$. Increasing concentrations of $\mathrm{PACl}$ decrease $\mathrm{pH}$ of CMP suspension proportionately. Positive charges of $\mathrm{PACl}$ reduced negative charges of silica colloids in CMP wastewater and reached neutrality at the concentration of $30 \mathrm{mg} / \mathrm{L}$

Fig. 3.6 (b) presents zeta potential of CMP suspension as function of PACl concentration. The results show the initial zeta potential of CMP wastewater to be at the level of $-59.5( \pm 0.7) \mathrm{mV}$. Fig. 3.6 (b) clearly shows zeta potential reduced gradually to $0 \mathrm{mV}$, with charge inversion at $30 \mathrm{mg} / \mathrm{L}$ and $\mathrm{pH}$ value of 5.9 . When $\mathrm{PACl}$ concentration was further increased to $35 \mathrm{mg} / \mathrm{L}$, zeta potential increased to $+31.5( \pm 0.2) \mathrm{mV}$. No negative charges were present with increased PACl concentration. The suspension became more positively charged leading to steric stabilization among the particles.

Fig. 3.6 (c) features z-average hydrodynamic diameter of CMP suspension as function of $\mathrm{PACl}$ concentration. Initial particle size amounted to $149.8( \pm 2.2)$ d.nm. As shown on fig. 3.6 (c), average particle size increased as more $\mathrm{PACl}$ was added. Charge inversion was observed at $30 \mathrm{mg} / \mathrm{L}$, with particle size at $8813( \pm 59)$ d.nm. Further increase of $\mathrm{PACl}$ concentration resulted in partial deagglomeration to $7346( \pm 19)$ d.nm at $\mathrm{pH}$ of 5.9 (Fig. 3.6 (a)). At this point, the particles dynamically underwent physical transformation via agglomeration. The agglomeration occurred at concentration range of 23 to $32 \mathrm{mg} / \mathrm{L}$. As the concentration of $\mathrm{PACl}$ increased beyond this point, the particles became more positively charged and partial deagglomeration occurred.

\subsection{Comparison between $\mathrm{FeSO}_{4} \cdot 7 \mathrm{H}_{2} \mathrm{O}$ and $\mathrm{PACl}$ in terms of interaction with CMP wastewater}

Comparison of fig. 3.5 (a) and fig. 3.6 (a) clearly shows that $\mathrm{pH}$ value drops more after adding $\mathrm{PACl}$ to $\mathrm{CMP}$ wastewater than after adding $\mathrm{FeSO}_{4} \cdot 7 \mathrm{H}_{2} \mathrm{O}$. This is due 
to the fact that initial $\mathrm{pH}$ value of $\mathrm{PACl}$ was lower in comparison to $\mathrm{FeSO}_{4} \cdot 7 \mathrm{H}_{2} \mathrm{O}$ - $\mathrm{PACl}$ is a stronger acid and has stronger effect on CMP wastewater.

Juxtaposing fig. 3.5 (b) and fig. 3.6 (b) shows that zeta potential at $\mathrm{FeSO}_{4} \cdot 7 \mathrm{H}_{2} \mathrm{O}$ concentration of $10 \mathrm{mg} / \mathrm{L}$ did not significantly differ as compared to $\mathrm{PACl}$, which influenced zeta potential from $-59.6( \pm 0.3) \mathrm{mV}$ to $-43.4( \pm 0.6) \mathrm{mV}$. Low positive zeta potential of $\mathrm{FeSO}_{4} \cdot 7 \mathrm{H}_{2} \mathrm{O}$ had less neutralizing effect than strongly negative zeta potential of CMP wastewater. Unlike $\mathrm{FeSO}_{4} \cdot 7 \mathrm{H}_{2} \mathrm{O}, \mathrm{PACl}$ had higher positive zeta potential values, which were able to reduce negative zeta potential values of CMP wastewater. This could be due to the fact that $\mathrm{Fe}^{2+}$ ions contributed less positive charges than $\mathrm{Al}^{3+}$ ions from $\mathrm{PACl}$. Therefore, $\mathrm{Al}^{3+}$ ions had greater ability to attract more negative charges to form agglomerates. Also, $\mathrm{Al}^{3+}$ ions are smaller in size than $\mathrm{Fe}^{2+}$ ions, so valence shells of $\mathrm{Al}^{3+}$ ions are closer to protons. This increases the attraction force, so negatively charged particles are attracted more easily.
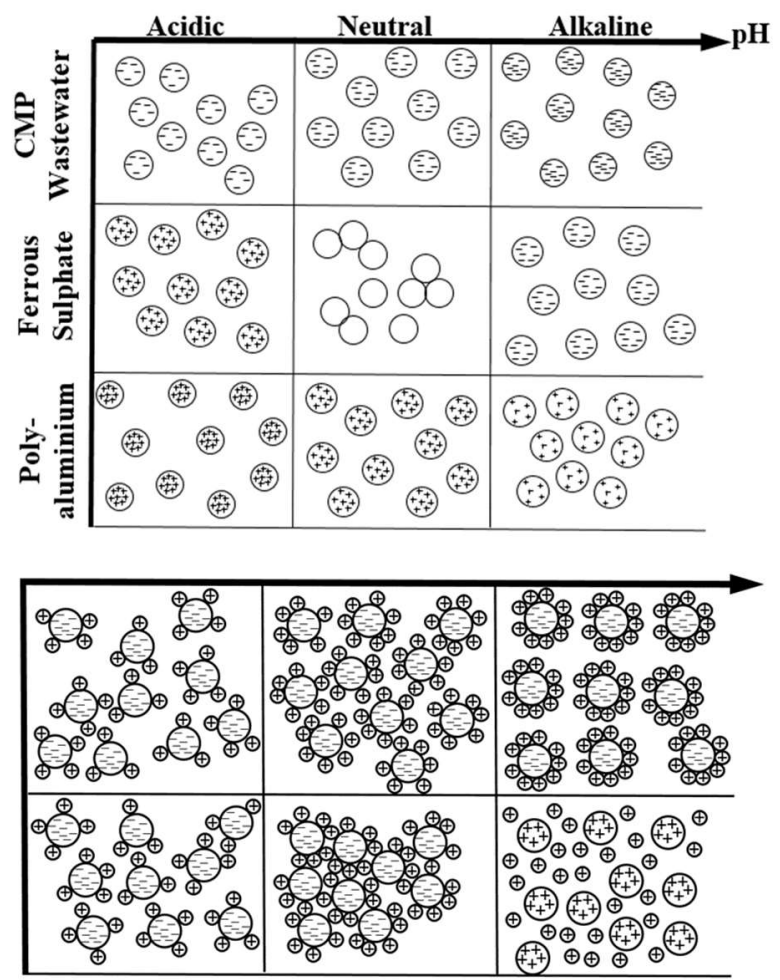

Fig. 3.7. Illustration of interactions of silica nanoscale colloids in CMP suspension with $\mathrm{FeSO}_{4} \cdot 7 \mathrm{H}_{2} \mathrm{O}$ and $\mathrm{PACl}$ coagulants in individual experiments 


\section{CONCLUSIONS}

The object of the research was chemical mechanical polishing wastewater containing silicon dioxide nanoscale colloids, with average zeta potential and particle size values measured at its initial $\mathrm{pH}$. The effect of changes in $\mathrm{pH}$ and coagulant concentration was studied on the basis of behavior of colloids in order to observe the strength of external factors affecting agglomeration properties of the suspension. The study proves that when $\mathrm{pH}$ value of CMP wastewater is adjusted towards acid, from $\mathrm{pH} 8.7$ to $\mathrm{pH} 2$, zeta potential decreases proportionately, reaching nearly $0 \mathrm{mV}$, while particle size corresponding to the same $\mathrm{pH}$ region is slightly increased. Two coagulant types were selected to interact with CMP wastewater in the study, i.e. $\mathrm{FeSO}_{4} \cdot 7 \mathrm{H}_{2} \mathrm{O}$ and $\mathrm{PACl}$. Similar evaluation was conducted for each coagulant in order to measure zeta potential and particle size variation as a function of $\mathrm{pH}$.

\section{ACKNOWLEDGEMENTS}

The authors would like to extend their appreciation to SiLTerra Malaysia Sdn. Bhd. for the contribution of wastewater samples in this research. This study is also collectively supported by the Ministry of Higher Education Malaysia (304.PAWAM.6314028), Short Term-USM Grant (304.PAWAM.60313041), RUI-USM Grant (1001.PAWAM.8014020), Bridging-USM Grant (304.PAWAM.6316094), L'Oreal-UNESCO Malaysian Fellowship (304.PAWAM.6050374.L117), International Foundation for Science and Organization for the Prohibition of Chemical Weapons (W/5334-2 and 304.PAWAM.6050364.1100).

\section{REFERENCES}

1. Aguilar, MI, Saez, J, Llorens, M, Soler, A and Ortuno, JF 2003. Microscopic observation of particle reduction in slaughterhouse wastewater by coagulation-flocculation using ferric sulphate as coagulant and different coagulant aids. Water Research 37, 2233-2241.

2. Brar, S, Verma, M, Tyagi, R and Surampalli, R 2010. Engineered nanoparticles in wastewater and wastewater sludge - evidence and impacts. Waste Management 30, 504-520.

3. Chang, FM and Liu, JC 2007. Precipitation removal of fluoride from semiconductor wastewater. Journal of Environmental Engineering 133, 419425.

4. Chou, WL, Wang, CT and Chang, SY 2009. Study of COD and turbidity removal from real oxide-CMP wastewater by iron electrocoagulation and the 
evaluation of specific energy consumption. Journal of Hazardous Materials 168, 1200-1207.

5. Chuang, TC, Huang, CJ and Liu JC 2002. Treatment of semiconductor wastewater by dissolved air flotation. Journal of Environmental Engineering 12, 974-980.

6. Decan, N, Wu, D, Williams, A, Bernatchez, S, Johnston, M, Hill, M and Halappanavar, S 2016. Characterization of in vitro genetoxic, cytotoxic and transcriptomic responses following exposures to amorphous silica of different sizes. Mutation Research/Genetic Toxicology and Environmental Mutagenesis 796, 8-22.

7. De Luna, MDG, Warmadewanthi and Liu, JC 2009. Combined treatment of polishing wastewater and fluoride-containing wastewater from a semiconductor manufacturer. Colloids and Surfaces A: Physicochemical and Engineering Aspects 347, 64-68.

8. Den, W and Huang, C 2005. Electrocoagulation for removal of silica nanoparticles from chemical-mechanical-planarization wastewater. Colloids and Surfaces A: Physicochemical and Engineering Aspects 254, 81-89.

9. Drouiche, N, Ghaffour, N, Lounici, H, Mameri, N, Maallemi, A and Mahmoudi, H 2008. Electrochemical treatment of chemical mechanical polishing wastewater: removal of fluoride - sludge characteristics - operating cost. Desalination 223, 134-142.

10. Higgin, R, Howe, K and Mayer, TM 2010. Synergistic behaviour between silica and alginate: novel approach for removing silica scale from RO membranes. Desalination 250, 76-81.

11. Hollingsworth, J, Sierra-Alvarez, R, Zhou M, Ogden, KL and Field, JA 2005. Anaerobic biodegradability and methanogenic toxicity of key constituents in copper chemical mechanical planarization effluents of the semiconductor industry. Chemosphere 59, 1219-1228.

12. Hsu. SC et al. 2011. Tungsten and other heavy metal contamination in aquatic environments receiving wastewater from semiconductor manufacturing. Journal of Hazardous Materials 189, 193-202.

13. Hu CY, Lo SL, Li CM and Kuan WH 2005. Treating chemical mechanical polishing (CMP) wastewater by electro-coagulation flotation process with surfactant. Journal of Hazardous Materials A120, 15-20.

14. Huang, CJ, Yang, BM, Chen, KS, Chang, CC and Kao, CM 2011. Application of membrane technology on semiconductor wastewater reclamation: a pilotscale study. Desalination 278, 203-210.

15. Huang, H, Liu, J, Zhang, P, Zhang, D and Gao, F 2017. Investigation on the simultaneous removal of fluoride, ammonia nitrogen and phosphate from 
semiconductor wastewater using chemical precipitation. Chemical Engineering Journal 307, 696-706.

16. Hunter, RJ 2001. Measuring zeta potential in concentrated industrial slurries. Colloids and Surfaces A: Physicochemical and Engineering Aspects 195, 205-214.

17. Keller A, Wang H, Zhou D, Lenihan H, Cherr G, Cardinale B, Miller R and Ji Z 2010. Stability and aggregation of metal oxide nanoparticles in natural aqueous matrices, Environmental Science and Technology 44, 1962-1967.

18. Kim, D, Kim, J, Ryu, HD and Lee, SI 2009. Effect of mixing on spontaneous struvite precipitation from semiconductor wastewater. Bioresource Technology 100, 74-78.

19. Kuan, WH and Hu, CY 2009. Chemical evidences for the optimal coagulant dosage and $\mathrm{pH}$ adjustment of silica removal from chemical mechanical polishing (CMP) wastewater. Colloids and Surfaces A: Physicochemical and Engineering Aspects 342, 1-7.

20. Lai, C and Lin, S 2003. Electrocoagulation of chemical mechanical polishing (CMP) wastewater from semiconductor fabrication, Chemical Engineering Journal 95, 205-211.

21. Lai, CL and Lin, SH 2004. Treatment of chemical mechanical polishing wastewater by electrocoagulation: system performances and sludge settling characteristics. Chemosphere 54, 235-242.

22. Lien, CY and Liu, JC 2006. Treatment of polishing wastewater from semiconductor manufacturer by dispersed air flotation. Journal of Environmental Engineering 132, 51-57.

23. Lin, SH and Yang, CR 2004. Chemical and physical treatments of chemical mechanical polishing wastewater from semiconductor fabrication. Journal of Hazardous Materials B108, 103-109.

24. Lin, W, Huang, Y, Zhou, X and Ma, Y 2006. In vitro toxicity of silica nanoparticles in human lung cancer cells. Toxicology and Applied Pharmacology 217, 252-259.

25. Liu, YH, Lin, CY, Huang, JH and Yen, SC 2016. Particle removal performance and its kinetic behaviour during oxide-CMP wastewater treatment by electrocoagulation. Journal of the Taiwan Institute of Chemical Engineers 60, 520-524.

26. Lin, SH and Jiang, CD 2003. Fenton oxidation and sequencing batch reactor (SBR) treatments of high-strength semiconductor wastewater. Desalination 154, 107-116.

27. Lin, SH and Kiang, CD 2003. Combined physical, chemical and biological treatments of wastewater containing organics from a semiconductor plant. Journal of Hazardous Materials B97, 159-171. 
28. Mulloy, K 2003. Silica exposure and systemic vasculitis, Environmental Health Perspectives 111, 1933-1938.

29. Ryu, HD, Kim, D and Lee, SI 2008. Application of struvite precipitation in treating ammonium nitrogen from semiconductor wastewater. Journal of Hazardous Materials 156, 163-169.

30. Sheikholeslami, R, Al-Mutaz, IS, Tan, S and Tan, SD 2002. Some aspects of silica polymerization and fouling and its pretreatment by sodium aluminate, lime and soda ash. Desalination 150, 85-92.

31. Tsai, JC, Kumar, M, Chen, SY and Lin, JG 2007. Nano-bubble flotation technology with coagulation process for the cost-effective treatment of chemical mechanical polishing wastewater. Separation and Purification Technology 58, 61-67.

32. Wang, CT, Chou, WL, Chen, LS and Chang, SY 2009. Silica particles settling characteristics and removal performances of oxide chemical mechanical polishing wastewater treated by electrocoagulation technology. Journal of Hazardous Materials 161, 344-350.

33. Yang, GCC and Li, CJ 2007. Electrofiltration of silica nanoparticlecontaining wastewater using tubular ceramic membranes. Separation and Purification Technology 58, 159-165.

34. Yang, GCC, Yang, TY and Tsai, SH 2003. Crossflow electromicrofiltration of oxide-CMP wastewater. Water Research 37, 785-792.

35. You, SH, Tseng, DH and Guo, GL 2001. A case study on the wastewater reclamation and reuse in the semiconductor industry. Resources, Conservation and Recycling 32, 73-81.

36. Zhang, Y, Chen Y, Westerhoff, P, Hristovski, K and Crittenden, JC 2008. Stability of commercial metal oxide nanoparticles in water. Water Research 42, 2204-2212.

Editor received the manuscript:26.09.2019 